\title{
EVALUATION OF HEALTH CONSEQUENCES OF AIR POLLUTION INDUCED BY BEAM ROLLING MILLS FACTORY (IRAN)
}

\author{
Masoud Rafiei ${ }^{1}$ A.S. Gadgil ${ }^{2}$, Hemlata Patil ${ }^{3}$ Tongdi Jamir $^{2}$
}

Key words: indoor, out door, smoker, non-smoker, occupational fatigue, cardiovascular disease.

\begin{abstract}
The increases in air pollution over the metropolitan cities are a threat to human health and environment. An attempt has been made to evaluate the health consequences of indoor air pollution induced by Beam Rolling Mills Factory at Ahwaz (Iran). A questionnaire was prepared to obtain information on health of 481 workers, out of which 200 each were selected from exposed and non-exposed category by stratified randomized method. Fisher exact test and chi-square test were used to calculate the values. The study concludes that more than $80 \%$ of the workers have high exposure risk to diseases. Analysis of the health impacts reveals that exposed workers are more prone to various diseases as compared to the non-exposed workers. It is also observed that exposure to air pollutants might be the causative factor for various diseases among the smokers but also nonsmoking workers. The analysis also reveals that there is higher relative risk in occupational fatigue and cardio-vascular disease. Further, the study found that percentage of workers having various diseases is much higher in the indoor environment as compared to the outdoor environment
\end{abstract}

\section{Introduction}

The increasing levels of air pollution in the metropolitan cities are posing serious threat to human health and environment and warrant rigorous control and management. Hence, monitoring and assessment is the primary step in these programs. In fact, standards and regulations prescribed till now to protect human health and welfare have been based on ambient air pollution levels. However, recently, it is being realized that ambient air observations obtained from central

1 Department of Occupational Health, Ahwaz Jundishapour University of Medical Sciences, Ahwaz, Iran, rafiei_2001@yahoo.com;

${ }^{2}$ Department of Environmental Science, University of Pune -411007, India

${ }^{3}$ Geography Department, University of Pune, Pune-411007, India 
monitoring stations do not accurately represent human exposures of "air people breathe" and hence corresponding risk to health. This is because of large spatial and temporal variations of air pollutants and because of diversity of human activities.

Several research studies highlighted that indoor air quality poses a serious threat to human health where people spend $80-90 \%$ of their time indoors in their residences, offices, shops etc (Simoni et al., 1998). There are also reports that of serious risks to health from exposure to PM in many cities of developed and developing countries (WHO report, 2005). The effects of inhaling PM have been studied on asthma, lung cancer, cardiovascular issues and premature deaths. The size of the particles is the main determinant in the respiratory problems (U.S. EPA, 2008).

Indoor air pollution is a major global public health problem requiring increasing efforts in research and policy making (Bruce et al., 2000). The concentration of several pollutants can be many times higher in indoor than outdoors (Book et al., 1991). Therefore, it is interesting to understand the quality of the indoor air we breathe in.

Several studies have investigated the effects of indoor air pollution on health of the infant children and elderly people (Jaakkola, 2000; Jaakkkola and Jaakkola, 2002). Numerous studies have reported links between air borne particles and a whole range of respiratory/cardiovascular symptoms, pulmonary function deficits and increased mortality (Abbey et al., 1995; Thurston et al., 1994; Wilson and Spengler, 1996). Some findings suggest that particle fractions significantly smaller than $\mathrm{PM}_{2.5}$ may be of great importance for human health (Dreher et al., 1996; Peters et al., 1997; Tsai et al., 2000). Other studies (Lin et al., 2002; Zhang et al., 2002) suggest that coarse particles are more closely associated with asthma. Premature mortality is usually found in individual with pre-existing cardio respiratory disease (Shwartz and Neas, 2000; Goloberg et al., 2001).

Emissions from the industries also contribute to air pollution. Particularly, Iron and Steel plants represent major sources of atmospheric pollution by dioxins (Evaraet and Baeyens, 2002, Gilpen et al., 2003). Studies were also conducted on the people living around the incinerators exposed to dioxin in Wallonia (Belgium) (Sebastien, 2007). Chemical factories like welding fumes containing manganese and other heavy metals may result in adverse health effect on the neurological, respiratory and cardiovascular system (Bowler et al., 2006). Some studies also reveal that steel workers with exposure to polluted workplace had $14 \%$ increased risk of lung and stomach cancer (Zhaoyi et al., 1998) and cancer morbidity (Yeon-Soon et al., 2006). On similar lines, several studies were conducted to assess the effect of pollution generated by iron and steel factories 
and risk to the health of workers as well as residence in the nearby areas (Chai et al., 2004; Hoshuyama et al., 2006; Amal et al., 2008; Bourgkard et al., 2008).

During recent years, the understanding of the mechanisms that control indoor air pollutions is of increasing interest among the scientific community as a result of growing concerns related to the effects on human health. More attention has been paid to occupational health impact at workplace particularly in mining, metal refining and metal working industry.

Iran's rapid economic growth is being built on a frame of steel. A soaring demand by sectors like infrastructure real estate and automobiles at home and abroad has put Iran steel industry on the world map. Iran rank $21^{\text {st }}$ in 2008 in terms of world steel productions produced 10 million tones. However, there are very few studies related to the indoor air pollution of the industries, in general, and from Iron and steel industry, in particular; therefore, the present study for the first time attempts to analyze the indoor air quality in Beam Rolling Mills Factory, Ahwaz, Iran.

With these considerations in background, the present papers attempts to evaluate the health consequences of pollution induced by Beam Rolling Mills Factory. This paper discusses the impact on health arising from the pollutants from the Beam Rolling Mills Factory.

\section{Materials and methods}

A questionnaire was prepared to obtain information related to demographic characteristic, educational qualification, their habits and the problems related to the health. Beam Rolling Mills Factory has 481 workers, out of which 200 workers were selected from exposed category. In addition 200 workers were selected from non-exposed category by stratified randomized method. These questionnaires were given to 200 exposed and 200 non-exposed workers, thus a cohort study was conducted among workers.

They were then matched, based on various criteria such as age, work experience, and smoking habits. All the 400 workers selected were asked to fill up the questionnaires. Data of questionnaire were analysed by SPSS software. Categorical analysis (Fisher exact test) was performed to calculate the Odd Ratio and $P$ values.

The Odd-Ratio is a widely accepted statistical method used to compare the frequency of exposure to risk factors in epidemiological studies. Calculating the Odd Ratio for a set of data which is fairly straight forward, 2X2 contingency table is first constructed. Then, computation of the Odd- Ratio is done,

Odds Ratio $=(\mathrm{A} / \mathrm{B}) /(\mathrm{C} / \mathrm{D})=(\mathrm{AXD}) /(\mathrm{BXC})$. 
If Odd Ratio is $>1$ and $\mathrm{P}<0.05$ only then Relative risk was computed. Relative Risk is the ratio of probability of the event occurring in the exposed group versus a non-exposed group (Sistrom et al., 2004).

$\mathrm{RR}=\mathrm{P}$ exposed $/ \mathrm{P}$ non-exposed.

Tab. 1: Relation between smoker/non-smokers with diseases

\begin{tabular}{ccc}
\hline Risk & \multicolumn{2}{c}{ Disease status } \\
& Present & Absent \\
\hline \hline Smoking & $a$ & $b$ \\
Not smoking & $c$ & $d$ \\
\hline
\end{tabular}

$$
\mathrm{RR}=\mathrm{a} /(\mathrm{a}+\mathrm{b}) / \mathrm{c} /(\mathrm{c}+\mathrm{d})
$$

Relative Risk was computed by using the odd ratio for exposed smokers, and workers having exposed cardiovascular diseases, complaining of chest tightness, cough, difficulty of remembering, work experience, tension, occupational fatigue, occupational stress etc are reported in Table 2 (a-e).

\section{Observations regarding the status of the workers}

Demographic features in terms of age of exposed and non-exposed workers are reported in Table 2.

Table 2(a): Age distribution of exposed workers

\begin{tabular}{|l|l|l|}
\hline Age (year) & $\mathrm{N}$ & $\%$ \\
\hline $30-39$ & 47 & 23.5 \\
\hline $40-49$ & 128 & 64.5 \\
\hline $50-59$ & 25 & 12.5 \\
\hline Total & 200 & 100 \\
\hline
\end{tabular}

Tab. 2.(b): Work experience and educational qualification

\begin{tabular}{|l|l|l|l|l|l|}
\hline Index & Exp. & Non-Exp. & Qualifications & Exp. & Non-Exp. \\
\hline$<11$ & $6(3 \%)$ & $18(9 \%)$ & Under diploma & $101(50.5 \%)$ & $20(10 \%)$ \\
\hline $12-17$ & $71(35 \%)$ & $94(47 \%)$ & Diploma & $57(28 \%)$ & $69(34 \%)$ \\
\hline $18-23$ & $100(50 \%)$ & $69(34 \%)$ & Pass Diploma & $18(9 \%)$ & $20(1 \%)$ \\
\hline $24-29$ & $19(9 \%)$ & $18(9 \%)$ & B.Sc. & $24(12 \%)$ & $79(39 \%)$ \\
\hline $30-35$ & $4(\% 2)$ & $1(0.05)$ & M. Sc or higher & $0(0 \%)$ & $12(6 \%)$ \\
\hline Total & 200 & 200 & Total & 200 & 200 \\
\hline
\end{tabular}


Tab. 2(c): Perception about cleanliness and lighting in work environment

\begin{tabular}{|l|l|l|l|l|l|}
\hline Cleanliness & Exp. & Non-Exp. & Lighting & Exp. & Non- Exp. \\
\hline R. clean & $4(2 \%)$ & $171(85 \%)$ & Very dark & $13(6 \%)$ & $0(\% 0)$ \\
\hline Dirty & $191(95 \%)$ & $29(14 \%)$ & SD & $141(70 \%)$ & $38(19 \%)$ \\
\hline Very dirty & $5(2 \%)$ & $0(0 \%)$ & Suitable & $46(23 \%)$ & $162(81 \%)$ \\
\hline Total & 200 & 200 & Total & 200 & 200 \\
\hline
\end{tabular}

Note: R- Reasonably

Table 2(d): Perception about noise and seating in work environment

\begin{tabular}{|c|c|c|c|c|c|}
\hline Noise & Exp. & Non- Exp. & Seating & Exp. & Non- Exp. \\
\hline Very suitable & $2(1 \%)$ & $15(7 \%)$ & Comfortable & $2412 \%)$ & $112(56 \%)$ \\
\hline $\mathrm{RS}$ & $6(3 \%)$ & $116(58 \%)$ & Uncomfortable & $3417 \%)$ & $76(38 \%)$ \\
\hline SS & $15(7 \%)$ & $48(24 \%)$ & $\mathrm{VC}$ & $3115 \%)$ & $7(3 \%)$ \\
\hline Not satisfactory & $177(88 \%)$ & $21(10 \%)$ & No exit & $111(55 \%)$ & $5(2 \%)$ \\
\hline Total & 200 & 200 & Total & 200 & 200 \\
\hline
\end{tabular}

Note: RS- Relatively suitable; SS-Somewhat satisfactory; VC- Very Uncomfortable

Table 2(e): Perception about satisfaction and climatic conditions

\begin{tabular}{|l|l|l|l|l|l|}
\hline Satisfaction & Exp. & Non-Exp. & CC & Suitable & Unsuitable \\
\hline VS & $1(0.05 \%)$ & $13(6 \%)$ & Hot season & $136.30 \%)$ & $187(93.50 \%)$ \\
\hline SS & $59(29 \%)$ & $115(57 \%)$ & Cold season & $120(60 \%)$ & $80(40 \%)$ \\
\hline NTS & $40(20 \%)$ & $50(25 \%)$ & Total & 133 & 267 \\
\hline NAAS & $100(50 \%)$ & $22(11 \%)$ & & & \\
\hline Total & 200 & 200 & & & \\
\hline
\end{tabular}

Note: CC-Climate conditions; VS-Very satisfactory; SS- Somewhat Satisfied; NTS- Not too satisfied; NAAS- Not at all satisfied.

It is clear from the above tables that: -

$88 \%$ of workers are reported in age-group $30-50$ years.

More than $80 \%$ of the workers have work experience between 12 and 23 years, indicating high exposure risk to the diseases.

$50 \%$ of exposed workers have education level only up to secondary school.

About $97 \%$ of the exposed workers reported indoor environment as dirty, particularly the powder spillage resulting from iron (approximately 10 tons per day).

$76 \%$ of the exposed workers complain about insufficient light conditions and that $95 \%$ suffer from noisy environments.

$93 \%$ workers endure from heat stress in their work place during hot season. 


\section{Analyses of the health impacts}

The factual information does not clearly answer the following explicitly: -

Whether the exposed workers are more prone to different diseases as compared to non-exposed workers?

Whether smokers are more susceptible to different diseases? If not, what other factors might be responsible for causing various diseases?

Among the various diseases, which disease reflects higher relative risk?

To answer these questions, the data was subjected to chi-square test with the following null hypotheses: -

1). $\mathrm{H}_{0}=$ There is no reason to assume that only exposed workers are prone to various diseases as compared to non-exposed workers.

$\mathrm{H}_{1}=$ There is at least a reason to assume that only exposed workers are prone to various diseases as compared to non-exposed workers.

A table 3 is constructed with set of diseases arising out of the exposed and non exposed conditions using the Tables 2 (a-e).

Table 3: Diseases among exposed and non- exposed workers

\begin{tabular}{|l|l|l|l|l|l|l|l|l|}
\hline Diseases & CV & CT & Cough & DIR & Tension & OF & UF & OS \\
\hline EW & 25 & 22 & 43 & 46 & 74 & 178 & 83 & 165 \\
\hline NEW & 9 & 9 & 20 & 24 & 47 & 22 & 42 & 35 \\
\hline
\end{tabular}

Note: CV-Cardio-vascular; CT- Chest Tightness; DIR-Difficulty in remembering OF-Occupational Fatigue; UF- Unusual Fatigue; OS- Occupational Stress; EWExposed worker; NEW-Non exposed workers.

$$
\begin{aligned}
\text { Calculated Value }\left(X^{2}\right) & =49.6773 \\
\text { Degrees of Freedom } & =7
\end{aligned}
$$

Critical value at 0.05 level of significance $=14.067$

Critical value at 0.01 level of significance $=18.475$

As the calculated value is greater than the critical value at both the levels of $95 \%$ \& $99 \%$, the null hypothesis is rejected and hence the alternative hypothesis $\mathrm{H}_{1}$ is accepted. Thus, there is at least some reason to assume that the exposed workers are more prone to various diseases as compared to the non-exposed workers.

In a similar manner in order to test whether only smoking is causative factor for the various diseases the following hypothesis is formulated:

2) $\mathrm{H}_{0}=$ There is no reason to assume that only smokers are prone to various diseases as compared to non-smokers. 
$\mathrm{H}_{1}=$ There is every reason to assume that only smokers are prone to various diseases as compared to non-smokers.

For this each disease has been separately tabulated and discussed in the subsequent paragraphs.

\section{Indoor environment}

As the calculated value is less than the critical value for all the health related problems, the null hypothesis is accepted and the alternative hypothesis is rejected, except in the case of chest tightness. Thus, we can conclude that in indoor environment, there is no reason to assume that only smokers are prone to various diseases as compared to non-smokers (Table 4).

Table 4: Workers (smokers and non-smokers) and the diseases in Indoor

\begin{tabular}{|c|c|c|c|c|c|c|c|c|}
\hline & \multicolumn{2}{|l|}{$\mathrm{CV}$} & \multicolumn{2}{|l|}{$\mathrm{CT}$} & \multicolumn{2}{|c|}{ Cough } & \multicolumn{2}{|l|}{ DIR } \\
\hline $\mathrm{D}$ & Yes & No & Yes & No & Yes & No & Yes & No \\
\hline $\mathrm{S}$ & 10 & 50 & 12 & 48 & 16 & 44 & 14 & 46 \\
\hline $\mathrm{NS}$ & 15 & 125 & 10 & 130 & 27 & 113 & 31 & 109 \\
\hline $\begin{array}{l}\text { Calculated } \\
\text { Value }\left(\chi^{2}\right)\end{array}$ & \multicolumn{2}{|c|}{1.361} & \multicolumn{2}{|c|}{7.092} & \multicolumn{2}{|l|}{1.356} & \multicolumn{2}{|l|}{0.034} \\
\hline & \multicolumn{2}{|c|}{ Tension } & \multicolumn{2}{|c|}{ OF } & \multicolumn{2}{|l|}{ UF } & \multicolumn{2}{|l|}{ OS } \\
\hline $\mathrm{D}$ & Yes & No & Yes & No & Yes & No & Yes & No \\
\hline $\mathrm{S}$ & 27 & 33 & 53 & 7 & 29 & 31 & 50 & 10 \\
\hline NS & 47 & 93 & 125 & 15 & 54 & 86 & 115 & 25 \\
\hline $\begin{array}{l}\text { Calculated } \\
\text { Value }\left(\chi^{2}\right)\end{array}$ & \multicolumn{2}{|l|}{2.353} & \multicolumn{2}{|c|}{0.039} & \multicolumn{2}{|l|}{1.649} & \multicolumn{2}{|l|}{0.041} \\
\hline \multicolumn{5}{|c|}{ Table value $\mathrm{S}$ and NS $0.05-3.841$} & \multicolumn{4}{|c|}{ Table Value S and NS 0.01-6.63 } \\
\hline
\end{tabular}

Note: CV- Cardio- vascular; CT- Chest Tightness; DIR-Difficulty in remembering; OF-Occupationa

Fatigue; UF- Unusual Fatigue; OS-Occupational Stress; D-Disease; S-smoking; NS-Not smoking.

\section{Outdoor environment}

As the calculated value is greater than the critical value, the null hypothesis is rejected and the alternative hypothesis is accepted. Thus, we can conclude that, in outdoor environment, there is every reason to assume that only smokers are prone to various diseases as compared to non-smokers.

\section{Conclusions}

Comparing the result of both indoor as well as outdoor environment, it is clearly evident that apart from smoking, there might be another factor responsible for various diseases in indoor environment. Thus, exposure to air 
pollutants might be the causative factor for various diseases among not only smoking workers but also non-smoking workers (Table 5).

Table 5: Workers (smokers and non-smokers) and the diseases in outdoor

\begin{tabular}{|c|c|c|c|c|c|c|c|c|}
\hline & \multicolumn{2}{|l|}{$\mathrm{CV}$} & \multicolumn{2}{|l|}{$\mathrm{CT}$} & \multicolumn{2}{|c|}{ Cough } & \multicolumn{2}{|l|}{ DIR } \\
\hline $\mathrm{D}$ & Yes & No & Yes & No & & & Yes & No \\
\hline $\mathrm{S}$ & 9 & 30 & 9 & 30 & 20 & 19 & 24 & 15 \\
\hline $\mathrm{NS}$ & 0 & 161 & 0 & 161 & 0 & 161 & 0 & 161 \\
\hline $\mathrm{CV}\left(\chi^{2}\right)$ & \multicolumn{2}{|c|}{38.905} & \multicolumn{2}{|c|}{38.905} & \multicolumn{2}{|c|}{91.738} & \multicolumn{2}{|c|}{112.587} \\
\hline & \multicolumn{2}{|c|}{ Tension } & \multicolumn{2}{|c|}{ OF } & \multicolumn{2}{|c|}{ UF } & \multicolumn{2}{|c|}{ OS } \\
\hline $\mathrm{D}$ & Yes & No & Yes & No & Yes & No & Yes & No \\
\hline$S$ & 39 & 0 & 22 & 17 & 39 & 0 & 35 & 4 \\
\hline $\mathrm{NS}$ & 8 & 153 & 0 & 161 & 3 & 158 & 0 & 161 \\
\hline $\mathrm{CV}\left(\chi^{2}\right)$ & \multicolumn{2}{|c|}{157.711} & \multicolumn{2}{|c|}{102.046} & \multicolumn{2}{|c|}{182.254} & \multicolumn{2}{|c|}{175.136} \\
\hline \multicolumn{5}{|c|}{ Table value $\mathrm{S}$ and NS $0.05-3.841$} & \multicolumn{4}{|c|}{ Table Value S and NS 0.01-6.635 } \\
\hline
\end{tabular}

Note: CV- Cardio- vascular; CT- Chest Tightness; DIR-Difficulty in remembering; OF-Occupational Fatigue; UF- Unusual Fatigue; OS-Occupational Stress, D-Disease; S-smoking; NS-Not smoking.

Further analysis was done to investigate which particular disease has highest factor in context of the health-related problems of the workers. To achieve this, Relative Risk Technique was employed (Table 6).

Table 6: Relative risk in percentage for various diseases

\begin{tabular}{|l|l|l|l|l|l|l|l|l|}
\hline \multicolumn{7}{|c|}{ Workers having various diseases in terms of percentage (\%) } \\
\hline Source & CV & CT & Cough & DIR & Tension & OF & UF & OS \\
\hline EW & 73.5 & 71 & 68 & 65 & 61 & 89 & 66 & 82.5 \\
\hline NEW & 26.5 & 29 & 32 & 35 & 39 & 11 & 34 & 17.5 \\
\hline RR & 2.78 & 2.44 & 2.15 & 1.92 & 1.57 & 3.90 & 1.98 & 2.09 \\
\hline
\end{tabular}

Note: CV-Cardio-vascular; CT- Chest Tightness; DIR-Difficulty in remembering; OF-occupational

Fatigue; UF- Unusual Fatigue; OS- Occupational Stress; RR-Relative risk.

It was found that maximum relative risk was observed in occupational fatigue $(\mathrm{RR}=3.90)$ followed by cardiovascular diseases $(\mathrm{RR}=2.78)$.

While monitoring the pollution levels, the present study has also noted the Wet Bulb Glob Temperature (WBGT) and the noise levels with the help of WBGT Set and Noise Meter respectively. NIOSH has recommended a standard of $25^{\circ} \mathrm{C}$ WBGT and $85 \mathrm{dBA}$ of noise level in heavy industries as criteria for healthy work environment. But here it was observed that the WBGT varied between $25^{\circ} \mathrm{C}-27^{\circ} \mathrm{C}$ and the noise levels were around $95 \mathrm{dBA}$, both far exceeding the NIOSH standards. This may be one of the reasons for higher relative risk in occupational fatigue and cardio-vascular disease. 
It is also observed from the above study that percentage of workers having various diseases is much higher in the indoor environment as compared to the outdoor environment. Unacceptable work condition (unhygienic, noisy and dark work environment) may have increased risk of these problems. Unsafe measures like lack of use of respiratory masks may be another contributor.

In order to improve the workplace environment, following strategies are recommended:

Generating awareness for using safety equipment.

Frequently calibrating the machines at the workplace.

Implementing strict measures for mandatory medical check-up of all the workers at regular intervals.

Noise absorber to the area when high amplitude of noise is produced

To reduce (dust) RSPM /SPM a trapping machinery be installed

\section{References:}

Simoni. M., Patrizia, B., Laura, C., Giovanni, V., Paolo, P., Gino, M., Gian, L.Z, Edmondo, I., Tristano, S. (1998), The Po River Delta (North Italy) Indoor Epidemiological Study: Home Characteristics, Indoor Pollutants, and Subjects, Daily Activity Pattern. Indoor Air, Vol. 8, 70-79 pages.

WHO report. (2005), World Health Organization. Avenue Appia 20, 1211 Geneva 27, Switzerland.

U.S. EPA. (2008), Report on the Environment (Final Report). U.S. Environmental Protection Agency, Washington.

Bruce, N., Perez-Padilla, R., Albalak, R. (2000), Indoor Air Pollution in Developing Countries: A Major Environmental and Public Health Challenge. Bulletin of World Health Organisation, Vol.78, 1078-1092 pages.

Book, B.O., Utter, G.M., De Broy, J.A., Schimke, R.D. (1991), Indoor Air Pollution: An Edifice Complex. Clinical Toxicology, Vol.29, 315-374 pages.

Jaakkola, M.S. (2000), Environmental Tobacco Smoke and Respiratory Diseases. European Respiratory Monograph, Vol.15, 322-383 pages.

Jaakkkola, J.J.K., Jaakkola, M.S. (2002), Effects of Environmental Tobacco Smoke on Respiratory Health in Children. Scandinavian Journal Work Environment Health, Vol.28, 71-83 pages.

Abbey, D.E., Ostro, B.E., Petersen, F., Burchette, R.J. (1995), Chronic Respiratory Symptoms Associated with Estimated Long term Ambient Concentrations of fine Particulates less than 2.5 microns in Aerodynamic Diameter (PM..5) and other Air Pollutants. Journal of Exposure Analysis and Environmental Epidemiology, Vol. 5, 137-159 pages.

Thurston, G.D., Ito, K., Hayes, C.G., Bates, D.V., Lippmann, M. (1994), Respiratory Hospital Admissions and Summertime Haze Air Pollution in Toronto, Ontario: Consideration of the Role of Acid Aerosols. Environmental Research, Vol. 65, 271290 pages. 
Wilson, R., Spengler,J. (1996), Particles in our Air Concentration and Health Effects. Harvard University Press, Boston, U.S.

Dreher, K., Jaskot, R., Richards, J., Lehmann, J., Winsett D, Hoffmann, A., Costa, D. (1996), Acute Pulmonary Toxicity of Site Fractionated Ambient Air Particulate Matter. American Journal of Respiratory and Critical Care Medicine, Vol. 153:A15 pages.

Peters, A., Wichmann, H.E., Tuch, T., Heinrich, J., Heyder, J. (1997), Respiratory Effects are Associated with the Number of Ultrafine Particles. American Journal of Respiratory and Critical Care Medicine, Vol.155, 1376-1383 pages.

Tsai, F.C., Smith, K.R., Vichit-Vadakan, N., Ostro, B.D., Chestnut, L.G., Kungskulniti, N. (2000), Indoor/Outdoor $P M_{10}$ and $P M_{2.5}$ in Bangkok, Thailand.Journal of Exposure Analysis and Environmental Epidemiology, Vol.10, 15- 26 pages.

Lin, M., Chen, Y., Burnett, R.T., Villenueve, P.J., Krewski, D. (2002), The Influenc of Ambient Coarse Particulate Matter on Asthma Hospitalization in Children: Case-

crossover and Time-series Analyses. Environ Health Perspective, Vol.110, 575-

581 pages.

Zhang, J., Hu, W., Wei, F., Wu, G., Korn, L., Chapman, R. (2002), Children's Respiratory Mortality Prevalence in Relation to Air Pollution in Four Chinese Cities. Environmental Heath Perspective, Vol.110, 961-967 pages.

Shwartz, J., Neas, L.M. (2000), Fine Particles are More Strongly Associated than Coarse Particles with Acute Respiratory Effects in Schoolchildren. Epidemiology, Vol.11, 6-10 pages.

Goloberg, M.S., Burnett, R.T., Brook, J., Bailar, J.C Jr., Valois, M.F., Vincent, R. (2001), Associations Between Daily Cause-Specific Mortality and Concentrations of Ground-Level Ozone in Montreal, Quebec. American Journal of Epidemiology, Vol.154, 817-826 pages.

Evaraet, K., Baeyens, J. (2002), The Formation and Emission of Dioxins in Large Scale Thermal Processes. Chemosphere, Vol.46, 439-448 pages.

Gilpen, R.K., Wagel, D.J., Solch, J.G. (2003), Production Distribution and Fate of Polycgrolirinated Dibenzo-P-Dioxin, Dibenzofurans, and Related Organohalogens in the Environment in Diozin and health. In Hoboken Schecter A， Gasiewiecz TA, Eds. John Wiley \& Sons.Inc 55-87 pages.

Sebastien, F. (2007), Impact of Iron and Steel Industry and Waste Incinerators on Human Exposure to Dioxins, PCBs, and Heavy Metals: Results of a CrossSectional Study in Belgium. Journal of Toxicology and Environmental Health, Part A, Vol.http://www.informaworld.com/smpp/title $\sim \mathrm{db}=$ all $\sim$ content $=\mathrm{t} 713667303 \sim \mathrm{tab}=$ issueslist $\sim$ branches $=70-$ v7070, $222-226$ pages.

Bowler, R.M., Koller, W., Schultz, P.E. (2006), Parkinsonism. Due to Manganism in a Welder Neurological and Neuropsychological Sequelae. Neurotoxicology, Vol.27, 327-32 pages.

Zhaoyi, X., Linda, M. B., Guo-Wei, P., Tie-Fu, L., Gun-Shen, G., Stone, B.J., ReiMing, C., De-Xian, G., Jia-Hua, S., Zuo-Shen, Y., Mustafa, D., Joseph, F., Fraumeni, Jr., William, J.B. (1998), Cancer Risks Among Iron and Steel Workers 
in Anshan, China, Part II: Case-control Studies of Lung and Stomach Cancer. American Journal of Industrial Medicine, Vol. 30, 7-15 pages.

Yeon-Soon, A., Robert, M.P., Leslie, S., Seong-Kyu, K., Jae-Kil, J. (2006, Cancer Morbidity in Iron and Steel Workers in Korea. American Journal of Industrial Medicine, Vol.49,647 - 657 pages.

Chai, Z.F., Qian, Q.F., Feng, X.Q., Zhang, P.Q., Liu, N.Q., Feng, W.Y., Kuang, M.X., Wang, H.Y., Zhang, Y.Z. (2004), Study of Occupational Health Impact of Atmospheric Pollution on Exposed Workers at An Iron and Steel Complex by using Neutron Activation Analysis of Scalp Hair. Journal of Radioanalytical and Nuclear Chemistry, Vol. 259, 153-156 pages.

Hoshuyama, T., Pan, G., Tanaka, C., Feng, Y., Yu, L., Liu, T., Liu, L., Hanaoka, T., Takahashi, K.A. (2006), Retrospective Cohort Study among Iron-Steel Workers in Anshan, China: Exposure Assessment. JUOEH Occupational Environmental Health Journal, Vol. 28, 253-263 pages.

Amal, E.S., Khalid, E.M., Sawsan, H., Neveen, A.M. (2008), Zinc Toxicity among Galvanization Workers in the Iron and Steel Industry. Annals of the New York Academy of Sciences, Vol.1140, 256 - 262 pages.

Bourgkard., Wild, E.P., Courcot, B., Diss, M., Ettlinger, J., Goutet, P., Hémon, D., Marquis, N., Mur, J.M., Rigal, C., Rohn-Janssens, M.P., Moulin, J.J. (2008), Lung Cancer Mortality and Iron Oxide Exposure in a French Steel-Producing Factory. Occupational and Environmental Medicine, Vol.66, 175-181 pages.

Sistrom, L., Cynthia, W., Garvan. (2004), Proportions, Odds, and Risk. Radiology, Vol. 230, 12-19 Pages. 